\title{
THE RATE OF SALMONELLA SPP. FROM HEALTHY PEOPLE IN HO CHI MINH CITY IN 2018
}

Nguyen Ly Hoang Ngan, Nguyen Do Phucl, Huynh Thi Kim Phan, Nguyen Thi Anh Dao Institute of Public Health Ho Chi Minh City

(Received on: 13/2/2019; Revised on: 30/3/2019; Accepted: 10/4/2019)

\begin{abstract}
Curvey results of 226 stool samples from healthy people collected from four districts in Ho Chi $\checkmark$ Minh city in 2018 (districts no. 1, 5, 8 and 9) showed that the number of people carrying Salmonella spp. was 12/226 (5.3\%). Twelve fecal samples were positive for Salmonella spp. with 15 Salmonella spp. strains isolated. Three of them are S. Indiana (20.0\%); S. Typhimurium, S. Rissen and S. Give. Each has two strains (13.3\%): 1 strain has serotypes O: 1 and one strains has 9: 1.5 (6.7\%). These Salmonella strains belong to the non-typhoid group (the group that causes diarrhea).

The Salmonella spp. strains isolated have highest antibiotic resistance to ampicillin, tetracycline, chloramphenicol (80.0\%); followed by sulfamethoxazole/trimethoprim (66.7\%); nalidixic acid (40.0\%); gentamicin, ciprofloxacin, kanamycin (26.7\%). Strains resistant to the third generation cephalosporins were found (cefotaxime and ceftazidime). Three of these are resistant to both types of antibiotics (20.0\%). No strains resistance to cefoxitin and cosfomycin were detected.
\end{abstract}

Keywords: Salmonella spp, Ho Chi Minh City.

\section{INTRODUCTION}

Salmonella spp is normally presented in livestock and poultry products such as eggs and milk. People eating these products may be at risk of being infected with Salmonella spp strain as well as carrying the pathogen, thus spreading it out into the land, water source and food stuff. So if rules of food safety are not strictly respected, healthy people carrying Salmonella could be a hazard to the social community. With $18.5 \%$ as the rate of infection (from the national objectives program about food safety in the period from 2011 to 2015 (March/2017-Hanoi)) of Salmonella spp in numerous types of food, this is one of four important reasons for diarrhea from micro-organisms. According to Vietnam's Ministry of Health, from January to November 2018, there were 547 diarrhea cases diagnosed as Salmonellosis.

In order to investigate the rate of healthy people containing Salmonella spp as well as assess the antibiotic resistance in Ho Chi Minh City, the survey was polled in four representative districts including districts no. 1, 5, 8 and 9 which differed from economic status, location and living condition. This study was taken with two main targets:

Find out the rate of healthy people carrying Salmonella spp and the serotypes of Salmonella spp in districts no. 1, 5, 8 and 9 of Ho Chi Minh city.

Find out the rate of antibiotic resistance of the strains isolated. 


\section{MATERIALS AND METHOD}

+ Method: cross-sectional study.

+ Time and location

Time: from $1 / 2018$ to $6 / 2018$.

Location: districts no. 1, 5, 8 and 9 of Ho Chi Minh City.

Sampling location: ward medical centers.

Testing centers: biology testing department, food safety quality control center in southern area, Institute of Public Health in Ho Chi Minh City

+ Research objects: Stool sample: randomly taken from healthy people living in sampling location at the age of 15 or above.

\section{- Sample size}

Sample size formula was employed to estimate the number of feces of healthy people.

$$
n=\frac{\left(Z_{1-\frac{\alpha}{2}}\right)^{2} \times p(1-p)}{d^{2}}
$$

Where: $n$ : sample size, $\mathrm{p}$ : the expected rate, $\mathrm{d}$ : desired width of confidence interval, $\alpha$ : type I error, $Z_{1-\alpha / 2}$ : coefficient respective to $\alpha$. According to Anders, $\mathrm{K} 1$ et al (2015), $\mathrm{p}$ was set at 0.18 , thus n was 226 .

\section{+ Cultures}

Selenite, XLD, TSI, LIM, TSB, SIM Media.

$\mathrm{O}$ and $\mathrm{H}$ antiserum (Denka Seiken Ltd., Tokyo, Japan; SSI Diagnostica, Hillerød, Denmark).

Antibiotic disk: antibiotics were used in treating diarrhea in healthy people infected with gram (-) of bacteria, also used in aquaculture and husbandry including ampicillin $10 \mu \mathrm{g}$ (AMP), tetracycline $30 \mu \mathrm{g}$ (TET), kanamycin $30 \mu \mathrm{g}$ (KAN), chloramphenicol $30 \mu \mathrm{g}$ (CHL), centamicin $10 \mu \mathrm{g}$ (GEN), trimethoprim $23.75 \mu \mathrm{g}$ and sulfamethoxazole $1.25 \mu \mathrm{g}$ (SXT), Ciprofloxacin $5 \mu \mathrm{g}$ (CIP), nalidixic acid $30 \mu \mathrm{g}$ (NAL), fosfomycin (FOF) $20 \mu \mathrm{g}$, cefoxitin $30 \mu \mathrm{g}$ (FOX), cefotaxime $30 \mu \mathrm{g}$ (CTX) and ceftazidime $30 \mu \mathrm{g}$ (CAZ). Combination of antibiotic disc CTX $30 \mu \mathrm{g}+$ clavulanic acid $10 \mu \mathrm{g}$ and CAZ $30 \mu \mathrm{g}$, and CAZ $30 \mu \mathrm{g}+$ clavulanic acid $10 \mu \mathrm{g}$ (BD, Sparks, MD).

+ Methods

+ Employ survey questionnaire to determine background information of the target;

+ Stool sample: collected from healthy people by using a cotton swab, anal swab and stored in Cary-Blair environment, stored cool and transported to the laboratory for testing Salmonella spp. according to the standard procedure for culturing and isolating Salmonella spp [12];

+ Antiserum of Salmonella spp was determined according to WHO Collaborating Center for Reference and Research on Salmonella, 2007 [2];

+ Antibiotic resistance of Salmonella spp was determined by Kirby-Bauer technique and cross-resistance was assessed according to the Clinical and Laboratory Standards Institute (CLSI), 2017 [3]. 3. RESULTS

\subsection{The rate of Salmonella spp contamination}

Table 1. The rate of Salmonella spp isolated from stool samples of healthy people

Stool containing Salmonella spp.

Positive

Negative
Frequency

12

5.3

214 
The result of Salmonella isolation from 226 stool samples showed that $5.3 \%$ of sample contributed to positive results.

Table 2. The percentages of Salmonella spp contaminated

\begin{tabular}{lrcc}
\hline \multicolumn{1}{c}{ District } & $\begin{array}{c}\text { The number } \\
\text { of sample }\end{array}$ & Frequency & Percentage (\%) \\
\hline No.1 & 50 & 2 & 4 \\
\hline No.5 & 60 & 2 & 3.3 \\
\hline No.8 & 60 & 2 & 3.3 \\
\hline No.9 & 56 & 6 & 10.7 \\
\hline
\end{tabular}

The distribution of Salmonella spp isolated differs from district to district, the highest proportion of Salmonella spp contamination was found in district no. $9(10.7 \%)$, the second highest was district no. $1(4 \%)$ and those of the other districts were at 3.3\% each.

Table 3. The percentage of serum type of Salmonella spp strains isolation $(n=15)$

\begin{tabular}{lccr}
\hline Type of serum & KN Formular & Frequency & Percen \\
\hline S. Indiana & 9 & 3 & 20.0 \\
S. Rissen & 1.8 & 2 & 13.3 \\
S. Give & 9 & 2 & 13.3 \\
S. Typhimurium & 9 & 2 & 13.3 \\
S. Kentucky & 5 & 1 & 6.7 \\
S. London & 5 & 1 & 6.7 \\
S. Meleagridis & 9 & 1 & 6.7 \\
S. Weltevreden & 9 & 1 & 6.7 \\
O: 1 & 8 & 1 & 6.7 \\
9: 1,5 & 1 & 1 & 6.7
\end{tabular}

In order to assesse the origin of the isolated Salmonella spp strains, their types of serum were determined. Among 12 samples that were positive to Salmonalla spp, there were 15 strains of Salmonella spp and 10 types of serum. In this study, there was one sample containing three strains of Salmonella spp, one sample containing two strains and the other 10 samples containing one strain.

\subsection{Result of antibiotic resistance of Salmonella spp isolated}

Table 4. The rate of antibiotic resistance of Salmonella spp isolated $(n=15)$

\begin{tabular}{lcc}
\hline \multirow{2}{*}{ Antibiotic } & \multicolumn{2}{c}{ Resistance } \\
\cline { 2 - 3 } & Frequency (n) & Percentage (\%) \\
\hline Ampicillin (AMP) & 12 & 80.0 \\
\hline Tetracycline (TET) & 12 & 80.0 \\
\hline Chloramphenicol (CHL) & 12 & 80.0 \\
\hline Sulfamethoxazole/rimethoprim (SXT) & 10 & 66.7 \\
\hline Nalidixic acid (NAL) & 6 & 40.0 \\
\hline Gentamicin (GEN) & 4 & 26.7 \\
\hline Ciprofloxacin (CIP) & 4 & 26.7 \\
\hline
\end{tabular}




\begin{tabular}{lcc}
\hline Kanamycin (KAN) & 4 & 26.7 \\
\hline Cefotaxime (CTX) & 3 & 20.0 \\
\hline Ceftazidime (CAZ) & 3 & 20.0 \\
\hline Cefoxitin (FOX) & 0 & 0 \\
\hline Fosfomycin (FOM) & 0 & 0 \\
\hline
\end{tabular}

In this study, 15 Salmonella strains had the highest antibiotic resistance to ampicillin, tetracycline, chloramphenicol $(80 \%)$, followed by sulfamethoxazole/rimethoprim at $66.7 \%$. This data for nalidixic acid was $40 \%$ and for gentamycin, ciprofloxacine and kanamycin were $26.7 \%$. Lowest resistance was found against cefotaxime and ceftazidime at $20.0 \%$ and there was no strain resistant to cefoxitin and fosfomycin.

Table 5. The distribution of serum type from its antibiotic resistance phenotype of Salmonella spp isolated $(n=15)$

\begin{tabular}{llc}
\hline \multicolumn{1}{c}{ Type of serum } & \multicolumn{1}{c}{ Resistant phenotype } & $\begin{array}{c}\text { Frequency } \\
\text { Percentage \%) }\end{array}$ \\
\hline S. Indiana & AMP, TET, KAN, CHL, GEN, CIP, NAL, & $3(20.0)$ \\
S. Kentucky & CTX, CAZ, SXT & \\
AMP, TET, KAN, CHL, GEN, CIP, NAL, & $1(6.7)$ \\
S. London & SXT & $1(6.7)$ \\
S. Rissen & AMP, TET, CHL, SXT & $1(6.7)$ \\
S. Typhimurium & AMP, TET, CHL, SXT & $2(13.3)$ \\
S. Meleagridis & AMP, TET, CHL, SXT & $1(6.7)$ \\
S. Weltevreden & AMP, TET, CHL, SXT & $1(6.7)$ \\
S. Give & AMP, CHL, SXT & $2(13.3)$ \\
S. Rissen & TET, CHL, NAL & $1(6.7)$ \\
O: 1 & AMP, TET & $1(6.7)$ \\
9: 1.5 & AMP & $1(6.7)$ \\
\hline
\end{tabular}

The result showed that there was one of the phenotypes of antibiotic resistance from Salmonella spp isolated from healthy human feces in four districts of Ho Chi Minh City (9:1.5) which was sensitive to all antibiotics in these experiments, while the multi-resistance strains (at least 3 antibiotic resistants) were at $80 \%$. This study also proved that three strains of $S$. Indiana resisted to 10 kinds of antibacterials.

The phenotype ESLB of the Salmonella spp resistant to cefotaxime and ceftazidime was then determined by combined dished method. The results indicated that all of them were positive to ESBL, which can produce large spectrum $\beta$-lactamase and resisted to the third generation of cephalosporin.

\section{DISCUSSION}

Salmonella spp is one of the agents causing diarrhea in human. In recent years, there has been an increasing number of antibiotic-resistant strains of Salmonella spp, which is an important health issue in the world. 
The percentage and types of serum of Salmonella spp isolated from stool samples of healthy people living in districts no. 1, 5, 8 and 9 in Ho Chi Minh City

Among 226 stool samples in four districts in Ho Chi Minh City, the percentage of Salmonella spp positive samples was 12/226 (5.3\%), which was higher than those from other study conducted in Mekong Delta (3.3\%) according to Trung NV et al [4]. This can be explained by the differences between economic conditions and living status of local residents.

In this study, the rate of Salmonella spp contaminations in four districts in Ho Chi Minh city was described. District no. 9 had the highest proportion of Salmonella spp contamination while the second highest data was found in district no.1. The reason may be derived from differences among living conditions, economic status of the and hygiene quality.

This is the first study about serotypes of Salmonella spp on healthy people carrying strains of Salmonella spp in Ho Chi Minh city. There were 15 strains of Salmonella spp isolated from 12 samples. There was only one Salmonella spp strain isolated from one sample in most of the cases. There were 10 people carrying one strain, one person carrying two strains and one person carrying three strains. Among 15 strains isolated, there were 10 different types of serum. S. Indiana accounting for $20 \%$, then S. Typhimurium S. Rissen and S. Give (13.3\%).

The isolated serotypes in this study were similar to serotypes isolated from fresh sustenance in Ho Chi Minh City in 2015 [5]. This result showed that the origin of food was responsible for healthy people carrying the strain of Salmonella spp. These serotypes belonged to non-typhoid group which is responsible for diarrhea.

\section{The ratio of Salmonella spp resistance to antibiotics}

The sensitivity of Salmonella spp was evaluated via isolation, multi-resistant phenotype (more than three antibiotics), the result was at 80\% (12/15). Ampicillin, Tetracycline, Chloramphenicol accounting for $80 \%$, Sulfamethoxazole/Trimethoprim was at $66.7 \%$. These antibiotics is normally used in treating diarrhea [6], human diseases and livestock industry related to Salmonella spp. The sensitivity of Nalidixic acid accounted for $40 \%$, that data for Ciprofloxacin was $26.7 \%$. These results were higher than results from Trung et al (2017) $(<2 \%)$ [4]. All strains of S. Indiana which was resistant to 10 types of antibiotics including Ciprofloxacin. These results were similar to Salmonella spp isolated from pork, beef, poultry, fish and shrimp in Ho Chi Minh City [5]. The spread of multiresistant antibiotics of Salmonella spp including Ciprofloxacin was a health issue for public in Ho Chi Minh city as well as Vietnam because these antibiotics were commonly used in disease related to Salmonella spp in humans.

In this study, there were three strains $S$. Indiana resistant to Cefotaxime and Ceftazidime, all of them were positively diagnosed with ESBL phenotype. The strains producing ESBL were detected around the world from food in Vietnam, and human in England [10]. Furthermore, the Salmonella spp strain producing ESBL normally co-resisted to Ciprofloxacin, which was a drawback in treatment [11]. This was a risk of spreading Salmonella spp from sustenances into healthy humans.

\section{CONCLUSION}

The rate of infection with Samonella spp. in healthy people in four districts in Ho Chi Minh City was at $5.3 \%$, of which district no. 9 had the highest prevalence $(10.7 \%)$ and the lowest was found in two districts no. 5 and no. 8 with the same infection rate at 3.3\%. Serotypes of Salmonella spp.: S. Indiana consists of three strains $(20.0 \%)$, followed by S. Typhimurium, S. Rissen and S. Give including two strains (13.3\%), while other serotypes have one strain accounting for $6.7 \%$.

The rate of antibiotic resistance of Salmonella spp strains isolated to antibiotics was as follows: Ampicillin, Tetracycline, and Chloramphenicol: $80.0 \%$; Sulfamethoxazole/Trimethoprim: 66.7\%; Nalidixic acid: 40.0\%; Gentamicin, Ciprofloxacin, Kanamycin: 26.7\%; There have been strains resistant to the third generation Cephalosporin: Cefotaxime and Ceftazidime, accounting for $20.0 \%$. 


\section{REFERENCES}

1. Anders K.L., Thompson C.N., Van Thuy N.T., et al. (2015), "The epidemiology and aetiology of diarrhoeal disease in infancy in southern Vietnam: a birth cohort study", Int. J. Infect. Dis, 35, pp. 3-10.

2. Grimont, P.A.D., andWeill, F-X. (2007), "Antigenic Formulae of the Salmonella Serovars", 9 ${ }^{\text {th }}$. WHO Collaborating Center for Reference and Research on Salmonella, Institute Pasteur, Paris, France.

3. CLSI (2017), "Performance standards for antimicrobial susceptibility testing", Twenty-seventh information supplement (M100-S26). Clinical and Laboratory Standards Institute, Wayne, PA.

4. Trung N.V et al, (2017), "Non+Typhoidal Salmonella Colonization in Chickens and Humans in the Mekong Delta of Vietnam". Zoonoses Public Health. 64 (2): 94-99.

5. Nguyen D.T.A., Kanki. M., Do N.P..et al. (2016), "Prevalence, antibiotic resistance, and extendedsectrum and AmpC $\beta$-lactamase productivity of Salmonella isolates from raw meat and seafood samples in Ho Chi Minh City, Vietnam”. International Journal of Food Microbiology.

6. Nguyen T.V., Le P.V., Le C.H., Weintraub A., (2005), "Antibiotic resistance in diarrheagenic Es cherchia coli and Shigella strains isolated from children in Hanoi,Vietnam". Antimicrobial Agents and Chemotherapy 49, 816-819.

7. Crump J.A., Medalla F.M., Joyce K.W., et al. (2011), “Antimicrobial resistance among invasive nontyphoidal Salmonella enterica isolates in the United States: National Antimicrobial Resistance MonitoringSystem, 1996 to 2007". Antimicrobial Agents and Chemotherapy 55, 1148-1154.

8. Pham D.K., Chu J., Do N.T., et al. (2015), "Monitoring antibiotic useand residue in freshwater aquaculture for domestic use in Vietnam", Ecohealth 12, 480-489.

9. Thai T.H., Hirai T., Lan N.T., Yamaguchi R., (2012), “Antibiotic resistance profile of Salmonella serovar isolated from retail pork and chicken meat in North Vietnam", International Journal of Food Microbiology 156, 147-151.

10. Liam B., Katie L. H., Daniele M., et al. (2014), "Resistance to third-generation cephalosporins in human non-typhoidal Salmonella enterica isolates from England and Wales, 2010-12", Journal of Antimicrobial Chemotherapy, Volume 69: 977 -981.

11. Whichard J.M., Gay K., Stevenson J.E., et al. (2007), "Human Salmonella and concurrent de creased susceptibility to quinolones and extended-spectrum cephalosporins". Emerg Infect Dis 13 (11):1681-1688.

12. “Testing process - Medical Microbiology”, Medical Publishing House, Hanoi, 2013, page 247-257

Tóm tắt

\section{TỶ LẸ NGƯỜI KHỎE MẠNH MANG VI KHUẨN SALMONELLA SPP. TẠI THÀNH PHỐ HỒ CHÍ MINH NĂM 2018}

Nguyễn Lý Hoàng Ngân, Nguyễn Đỗ Phúc, Huỳnh Thị Kim Phấn, Nguyễn Thị Anh Đào Viện Y tế Công cộng thành phố Hồ Chí Minh

Kết quả khảo sát 226 mẫu phân người khỏe mạnh thu thập từ 4 quận (quận $1,5,8$ và 9) của thành phố Hồ Chí Minh cho thấy số người mang vi khuẩn Salmonella spp. là 12/226 (5,3\%). Có 12 mẫu phân dương tính với Salmonella spp., đã phân lập được 15 chủng Salmonella spp. Ba chủng là $S$. Indiana (20,0\%); $S$. Typhimurium, $S$. Rissen và $S$. Give, mỗi loài có 2 chủng (mỗi loại 13,3\%), 1 chủng có kiểu typ huyết thanh $O 1$ và 1 chủng 9: 1, 5 (mỗi loại 6,7\%). Các chủng Salmonella spp. này thuộc nhóm nontyphi (nhóm gây tiêu chảy).

Tỷ lệ vi khuẩn Salmonella spp. đề kháng kháng sinh cao nhất là Ampicillin, Tetracycline, Chloramphenicol $(80,0 \%)$; kế đến là Sulfamethoxazole/trimethoprim $(66,7 \%)$; Nalidixic acid (40,0\%); Gentamicin, Ciprofloxacin, Kanamycin (26,7\%); đã xuất hiện chủng đề kháng với nhóm Cephalosporin thế hệ 3: Cefotaxime và Ceftazidime, có 3 chủng đề kháng 2 loại kháng sinh này chiếm tỷ lệ (20,0\%); chưa có chủng đề kháng Cefoxitin và Fosfomycin.

Tù khóa: Người khỏe mạh mang Salmonella spp. tại TP. Hồ Chí Minh 